\section{Everyone listed on Dolly paper met established criteria for authorship}

SIR - Your Special Report ${ }^{\alpha}$ Credit where credit's due" (Nature 440, 591-592; 2006) is critical of the extent of Ian Wilmut's claims to credit for Dolly the cloned sheep, as well as of authorship issues connected with the publication of her creation (Nature 385, 810-813; 1997).

Wilmut has modestly stated that his role in the research was mainly a supervisory one, and that others, principally Keith Campbell, deserved more of the intellectual credit. These comments, together with those made by a disaffected previous member of Wilmut's group, were seized upon irresponsibly by Nature.

As someone intimately involved at all stages of the Dolly project, I am confident that authorship was properly assigned and that due credit has been given.

Dolly came into existence as a result of Wilmut's efforts to attract funding for nuclear-transfer research and his recruitment of excellent staff to pioneer innovative techniques. These amply justify his public standing as the person most clearly associated with Dolly, an outcome that has unfortunately been confused with apportionment of credit.

Dolly resulted from the combined efforts of scientists, veterinary surgeons, farm managers and farmhands, most of whom were not listed as authors.

To qualify as an author, one should have made key intellectual and/or novel technical contributions - inclusion of all, irrespective of the nature and extent of their contribution, can devalue the currency of those who are chiefly responsible for a project's success.

All the individuals listed on the Dolly paper, including Wilmut, met established criteria for authorship. The technical breakthrough that made Dolly possible was published by Wilmut and his team in 1996 (Nature 380, 64-66; 1996), one year before the Dolly paper. But the content of scientific papers that chronicle major discoveries is not always aligned with the impact those papers make and, unsurprisingly, of the two, the Dolly publication took the lion's share of public attention.

Authorship is an important issue for the scientific community and for scientific journals. Important steps are being taken to ensure that authorship is properly credited, as you mentioned in your Special Report.

But authorship issues are not limited to papers about doning and stem cells. Such a focus could, in the present climate, provide further ammunition to those wishing to smear the integrity of all involved in this important area of scientific research.

Alan Colman

ES Cell International Pte Ltd,

11 Biopolis Way, \#05-06 Helios,

Singapore 138667

We reject the suggestion that we were irresponsible in factually reporting the dispute relating to Dr Wilmut in the context of an account of disputes about credit; in no way, explicitly or implicitly, did we suggest that he was at fault. Editor, Nature.

\section{It's incredible how often we're surprised by findings}

SIR - How often do natural scientists admit surprise at their findings? More frequently than social scientists or nonscientists? I searched for words indicating surprise among 30,133,141 abstracts of English-language scientific papers indexed in the Science Citation Index (SCI) and 8,151,087 English-language academic articles in the Social Sciences and Arts \& Humanities citation indices. I compared the frequencies of words appearing in the SCI with their frequencies in the other indices and, separately, with their occurrence in general writing, as recorded in the Brown Corpus of Standard American English (edict.com. $\mathrm{hk}$ /lexiconindex), by testing the significance of log-odds ratios (all were found to be significant at $P<0.001$ ).

The study of nature does indeed seem to surprise us. The odds of finding in abstracts of scientific research papers a result or conclusion described as 'surprising', 'unexpected', or 'unusual' are an order of magnitude greater than in standard language and several times greater than in non-science academic abstracts.

The word 'surprising' appears 12 times more frequently in the natural sciences than in standard English and 1.3 times more frequently than in social sciences, arts and humanities. The word 'unexpected' appears 39 times and 2.2 times more frequently in the natural sciences than, respectively, in standard English and in non-science academic writing.

In contrast, words such as 'happy', 'unhappy' or 'ugly' occur with frequencies that are expectedly lower in the natural sciences than elsewhere (further details of this research are available on request from jasienski@post.harvardedu).

Although natural phenomena can indeed sometimes be surprising if they are against our expectations, being 'surprising' is not an inherent quality of nature. Does scientists' use of this term in their publications truly represent genuine surprise at their results?
One might think that academic machismo or realism would cause scientists to downplay their surprise, but, on the other hand, overstating the level of astonishment may occur when striving for media attention. Michal Jasienski

Nowy Sacz Business School-

National-Louis University, Zielona 27, 33-300 Nowy Sacz, Poland

\section{Funding should recognize outcome, not income}

SIR - I was disappointed to read in your Editorial "Brown's budget briefing" (Nature 440,581;2006), discussing a future replacement for the UK Research Assessment Exercise (RAE), that you consider "external research income" as "a reasonable basis for departmental funding".

I hope it is still true to say that no major scientific prizes or seats at the high tables of science have been awarded on the basis of an individual's research income. Although external research income has been a significant - some might say disproportionate - factor in previous RAEs, it should not become a substitute for scientific excellence.

For scientists, the only significant research outcome is the science and, primarily, its communication through publication. Scientists are all too aware of instances of poor accountability in the spending of highly competitive research grants - the result of grant-giving bodies supporting the idea and not the individual.

A scientific meritocracy based upon success in gaining research funding is wholly reversible. But there are no instances of scientists whose success has been measured by their output, on the other hand, being asked to leave their seats at science's high table, their Nobel prizes in envelopes marked "Return to sender".

In other words, the measure of scientific success is scientific output - the elucidation of new knowledge and its dissemination through publication - and not science income.

Awarding science funding primarily upon the basis of the latter will only ensure a decline in the former.

Christopher Exley

Birchall Centre for Inorganic Chemistry and MaterialsScience,

KeeleUniversity,

Staffordshire ST5 5BG, UK

Contributions to Correspondence may be submitted to corres@nature.com. They should be no longer than 500 words, and ideally shorter. They should be signed by no more than three authors; preferably by one. Published contributions are edited. 